\title{
The prevalence of type 2 diabetes in patients with COVID-19: a systematic review and meta-analysis
}

\section{ABSTRACT}

Background. A strong link between morbidity and mortality from COVID-19 and diabetes mellitus is reported by many studies. The present study estimated the pooled prevalence of diabetes in patients with COVID-19.

Material and methods. International scientific databases were searched until 15 April 2020. There was no limitation in time and language of the published papers. Quality assessment of studies was performed using the Newcastle-Ottawa Scale (NOS) checklist. The random effects model was used to report the pooled prevalence with $95 \%$ confidence interval $(\mathrm{Cl})$.

Results. The pooled prevalence of diabetes in patients with COVID-19 was $14 \%$ (95\% Cl: 11.17). Due to high heterogeneity $\left(\mathrm{I}^{2}\right.$ of $\left.93.4 \%, \mathrm{P}<0.001\right)$, three subgroups were analyzed based on study location, age and sex. The prevalence of diabetes $(P)$ was higher among male patients ( $P=16 \%, 95 \% \mathrm{Cl}: 0.12,0.20)$, patients aged $\geq 65$ years $(P=19 \%, 95 \% \mathrm{Cl}: 0.08,0.31)$. The prevalence of diabetes was $15 \%(95 \% \mathrm{Cl}: 0.10,0.20)$ among patients in Wuhan, China and $10 \%$ in patients in other cities in China (95\% Cl: $0.06,0.15)$, and $39 \%$ in patients from other countries $(95 \% \mathrm{Cl}: 0.04,0.74)$.

Address for correspondence: Shahrzad Nematollahi

Men's Health and Reproductive

Health Research Center

Shahid Beheshti University

of Medical Sciences, Tehran, Iran

e-mail: shrzd.nematollahi@sbmu.ac.ir

Clinical Diabetology 2020, 9; 5: 271-278

DOI: $10.5603 /$ DK.2020.0041

Received: 08.09.2020

Accepted: 20.09.2020
Conclusion. According to the results of this systematic review, the prevalence of diabetes in patients with COVID-19 is higher in other countries compared to China. The prevalence of diabetes among COVID-19 patients was also significantly higher in men and elderlies. This evidence may be useful for health policymakers to design suitable preventive and therapeutic interventions in patients with diabetes and COVID-19. (Clin Diabet 2020; 9; 5: 271-278)

Key words: COVID-19, diabetes mellitus, prevalence, systematic review

\section{Introduction}

The outbreak of the new coronavirus disease (COVID-19) from Wuhan, China, began in December 2019 [1] and has been declared as a global emergency by the World Health Organization [2]. People with diabetes mellitus (DM) usually present a more severe morbidity and mortality from COVID-19 [3, 4]. Studies have shown that underlying conditions such as cardiovascular diseases, diabetes, hypertension, and chronic obstructive pulmonary disease (COPD) can exacerbate COVID-19 $[5,6]$. There is a significant difference in the mortality of COVID-19 in people with diabetes compared to patients free of diabetes. This proportion varies from $9.7 \%$ to $85.54 \%[7,8]$. A two-fold increase in the chance of COVID-19 mortality among people with diabetes is also reported [9]. Diabetes is one of the most common diseases in the world [10] and its association with COVID-19 disease has been confirmed by many studies [11]. However, the reliability of these findings might be confounded by low sample size and scale of the studies. To get more convincing results, we 
conducted a systematic review and meta-analysis for estimation of the prevalence of diabetes in patients with COVID-19. Notwithstanding, we used both types of diabetes (including diabetes mellitus and type 1 diabetes) in our review of the literature.

\section{Material and methods}

\section{Searching strategy}

International scientific databases including Web of science, Scopus and PubMed were searched until 15 April 2020. In the PubMed search, we used the following combination of key terms: diabetes mellitus OR diabetes type 2 OR diabetes OR diabetes type 1 AND COVID-19 OR "SARS COV-2" AND prevalence. In the Web of science and Scopus, we used a combination of key terms: COVID-19, SARS COV-2, coronavirus and diabetes, diabetes mellitus.

\section{Inclusion/exclusion criteria}

All cross-sectional studies reporting prevalence of diabetes in patients with COVID-19 were eligible for the study. There was no limitation in the time and language of the published papers. Exclusion criteria included other types of observational studies (including letter to the editor, review articles, and case reports), books, editorials, conference abstracts, and notes. These studies did not include the minimum data required for extraction.

\section{Data collection}

To ensure the correct selection of articles according to the inclusion criteria, two researchers (MFG and NA) were responsible for selecting articles independently. In cases of a disagreement, it was decided through negotiations with the third person (HM). First, all articles related to the prevalence of diabetes as well as articles related to COVID-19 were collected. At this stage, screening was conducted on all articles based on the keywords in their title or abstract. Then, fulltest of articles reporting the prevalence of diabetes in patients with COVID-19 were assessed thoroughly. The following variables were extracted from the selected studies: name of the first author, study location, sample size, number of people with diabetes and COVID-19, median age, gender, type of diabetes and diagnosis method for COVID-19. Quality assessment of studies was performed using the Newcastle-Ottawa Scale (NOS) checklist. Using the Newcastle-Ottawa Scale (NOS), we used selection and outcome domains with the following items: representativeness of the sample, determining the sample size, assessing the outcome, and statistical tests [12]. The evaluation was done independently by three researchers (MFG and NA and
$\mathrm{SN})$. Any disagreement between the researchers were resolved through negotiation.

Heterogeneity assessment and statistical analysis

Heterogeneity of studies was determined by the forest plot diagram and statistical tests. The statistical tests included Chi-square, $X^{2}, I^{2}$ and $\operatorname{Tau}^{2}[13,14]$. The random effects model was used to report the results with $95 \%$ confidence interval $(\mathrm{Cl})$. We used Stata 14 software to analyze the data.

\section{Results}

\section{Search and selection}

A total of 216 articles were retrieved initially including 187 records in the PubMed database, 18 records in the Web of science database, 11 records in the Scopus database. After the duplication removal, a total of 182 articles remained including 176 in the PubMed database and 6 in the Web of science database. After reviewing the title and abstracts, 23 articles that reported the prevalence of diabetes in people with COVID-19 were entered the data extraction phase and the rest of the articles were excluded. Using the NOS checklist, the quality of 23 articles was evaluated and finally 20 articles (total sample size of 5515) were entered into the meta-analysis. The studies included cross-section and case series. Of the 20 studies that entered into the meta-analysis, most were conducted in Wuhan, China $(n=12,60 \%)$ and six (28.5\%) were conducted in other parts of China and only two (10\%) in other countries (France and the United States) (Figure 1).

\section{Heterogeneity test}

According to the results of the chi-square test, heterogeneity of studies was significantly high, yielding an $\mathrm{I}^{2}$ of $93.4 \%(\mathrm{P}<0.001)$. Although we could not combine these studies, we reported an estimate of the prevalence of diabetes in patients with COVID-19. As a result, to reduce heterogeneity, we divided the included studies into subgroups based on study location, age, and gender.

\section{Estimate of prevalence}

The prevalence of diabetes in patients with COVID-19 was $14 \%$ (95\% Cl: 11,17\%) (Figure 2). The lowest prevalence of diabetes in patients with COVID-19 (2.7\%) was reported by Wang, Xiaobing et al. [15] in Wuhan, China, and the highest prevalence (58\%) was reported in Washington DC, the US [16] (Figure 3). The mean $( \pm \mathrm{SD})$ of prevalence in the remaining studies was $17 \%$ ( $\pm 12 \%$ ) (Tables 1, 2). In this study, the Egger test was used to diagnose publication bias, and the Egger test was significant $(P=0.001)$ and had a confidence 


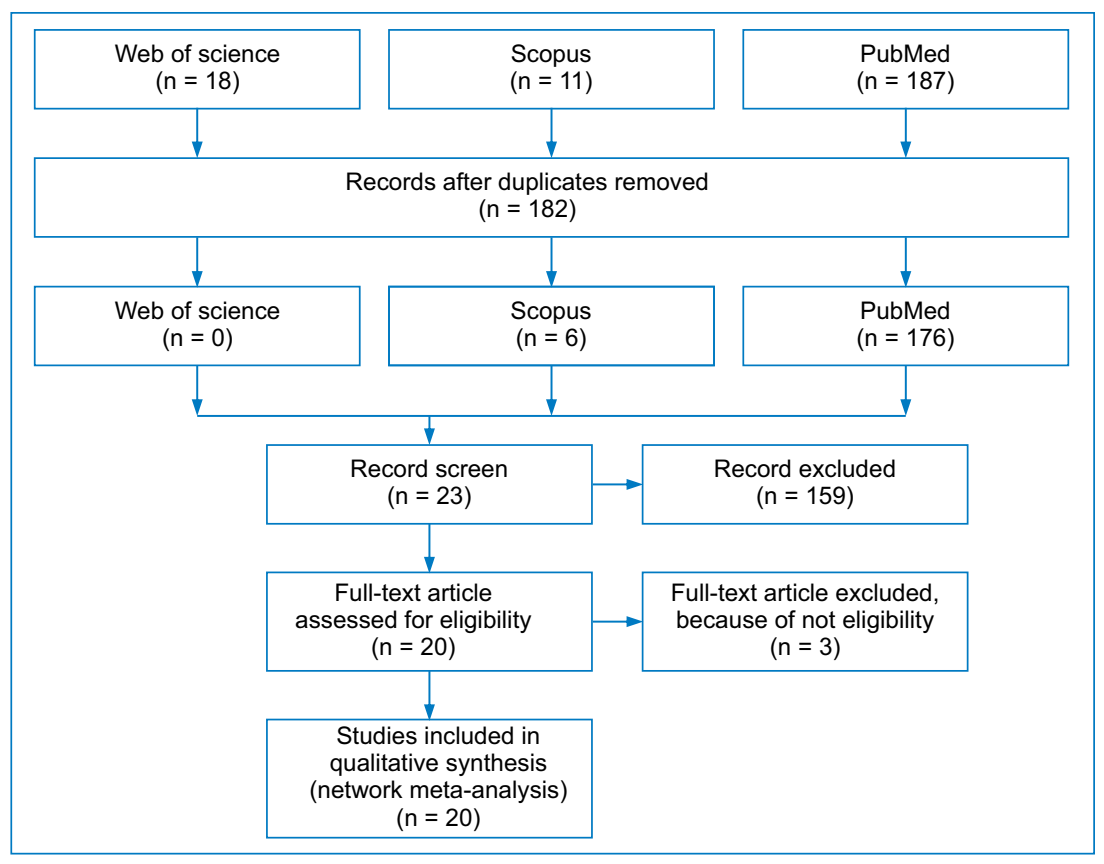

Figure 1. PRISMA flow diagram of the included studies

\begin{tabular}{|c|c|c|c|}
\hline \multicolumn{2}{|l|}{ Study } & \multirow{3}{*}{$\begin{array}{l}\text { ES }(95 \% \mathrm{Cl}) \\
0.18(0.15,0.21)\end{array}$} & \multirow{3}{*}{$\begin{array}{l}\% \\
\text { Weight } \\
6.55\end{array}$} \\
\hline \multicolumn{2}{|l|}{ ID } & & \\
\hline Lian, J. & - & & \\
\hline Chen, C. & $\rightarrow$ & $0.10(0.05,0.15)$ & 5.93 \\
\hline Zhao, S. & $\rightarrow$ & $0.11(0.01,0.21)$ & 4.07 \\
\hline $\mathrm{Li}, \mathrm{X}$. & & $0.40(0.21,0.59)$ & 1.94 \\
\hline Zhang, J. J. & $\leftarrow$ & $0.09(0.05,0.13)$ & 6.18 \\
\hline Wang, $X$. & - & $0.03(0.02,0.04)$ & 6.82 \\
\hline Zhou, F. & - & $0.19(0.13,0.24)$ & 5.67 \\
\hline Wan, S. & $\rightarrow$ & $0.09(0.04,0.14)$ & 5.93 \\
\hline $\mathrm{Du}, \mathrm{Y}$. & 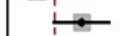 & $0.22(0.13,0.31)$ & 4.46 \\
\hline Leung, C. & $\rightarrow-$ & $0.24(0.12,0.37)$ & 3.30 \\
\hline Chaolin Huang & - & $0.20(0.07,0.32)$ & 3.41 \\
\hline Guan, W. J. & - & $0.08(0.07,0.10)$ & 6.78 \\
\hline Wang, L. & + & $0.03(0.01,0.05)$ & 6.70 \\
\hline Bhatraju, P. K. & & $0.58(0.39,0.78)$ & 1.87 \\
\hline Guo, W. & - & $0.21(0.15,0.27)$ & 5.48 \\
\hline Zhou, J. & $\rightarrow$ & $0.10(-0.01,0.21)$ & 3.72 \\
\hline Wu, J. & + & $0.07(0.04,0.10)$ & 6.46 \\
\hline Simonnet, A. & $\rightarrow$ & $0.23(0.15,0.30)$ & 5.00 \\
\hline $\mathrm{He}, \mathrm{X} . \mathrm{W}$. & 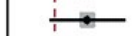 & $0.24(0.13,0.35)$ & 3.63 \\
\hline Wu, C. & $\Rightarrow$ & $0.11(0.07,0.15)$ & 6.09 \\
\hline Overall $(I-$ squared $=93.4 \%, p=0.000)$ & $\diamond$ & $0.14(0.11,0.17)$ & 100.00 \\
\hline \multicolumn{4}{|c|}{ NOTE: Weights are from random effects analysis? } \\
\hline-.781 & 0 & 81 & \\
\hline
\end{tabular}

Figure 2. Funnel plot for prevalence of diabetes in patients with COVID-19. \% heterogeneity $=93.4 \%$ (95\% Cl); P for heterogeneity $=0.001$ 


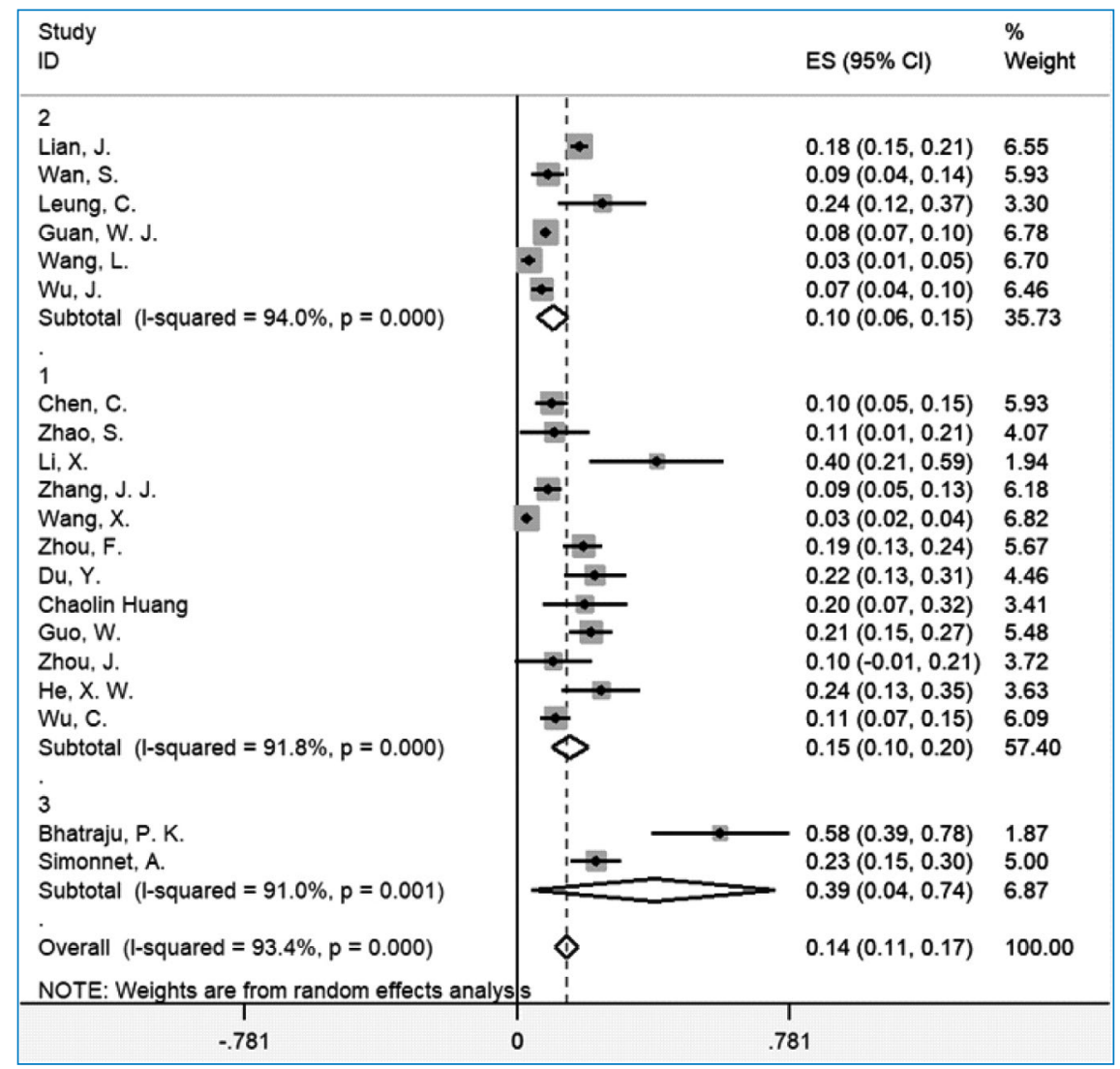

Figure 3. The results of meta-analysis of prevalence of diabetes in patients with COVID-19 according to study location. 1 - Wuhan, China; 2 - other place in China; 3 - other countries (France and Washington in the United States)

interval of 2.28 to 5.85 , indicating a publication bias (Figs 6, 7).

\section{Discussion}

Currently, the geographical spread and mortality of COVID-19 disease, as well as the rapid transmission of the disease, have raised concerns among countries [17]. So far, there is not any confirmed medication for COVID-19 while the situation gets worsen in those with diabetes. In this subgroup of patients, COVID-19 progresses rapidly, and respiratory failure can occur in a short time, which probably leads to death $[18,19]$. The most common symptoms among diabetic patients with COVID-19 were fever (85.6\%), cough (68.7\%) and fatigue (39.4\%). The most common comorbidities included high blood pressure (17.4\%), hypertension (17.4\%), diabetes (3.8\%), and coronary heart disease (3.8\%). A recent study and meta-analysis of 24 studies confirmed that fever and cough are the most common symptoms in COVID-19 patients with diabetes mellitus [20]. Our study showed that the prevalence of diabetes in patients with COVID-19 was $14 \%$. However, a systematic review of 1556 patients in 24 studies by Andrea Lovato et al. on the prevalence of diabetes in patients with COVID-19 showed that the prevalence in these patients was 3.8\% [20]. This difference may be due to differences in sample size, location of the study, data collection technique, and the sex and age of the patients. In our study, the prevalence was very different, from 2\% [15] in China to 58\% [16] in Washington. Due to the high heterogeneity, we preferred to classify these studies according to subgroups.

Due to the change in the prevalence of diabetes in people with COVID-19 in different regions, we divided the geographical areas into three categories: Wuhan in China, other cities in China and other countries. The prevalence of diabetes in Wuhan, China (15\%) was higher than other Chinese cities (10\%). In countries like the United States and France, it was more than twice as high as in China (39\%). Another risk factor for unchanged COVID-19, which has been the subject of numerous studies, is gender [21, 22]. Our study found that more than 50 percent of diabetic patients with COVID-19 were men. Older age is another factor that has led to a higher incidence of diabetes in people with COVID-19 [22].Our study identified age over 65 as a risk factor and found that 20 percent of elderly patients with COVID-19 had diabetes. Obviously, one must be very careful in interpreting these results because our study has several limitations. The main limitation of the study was related to the low quality of 


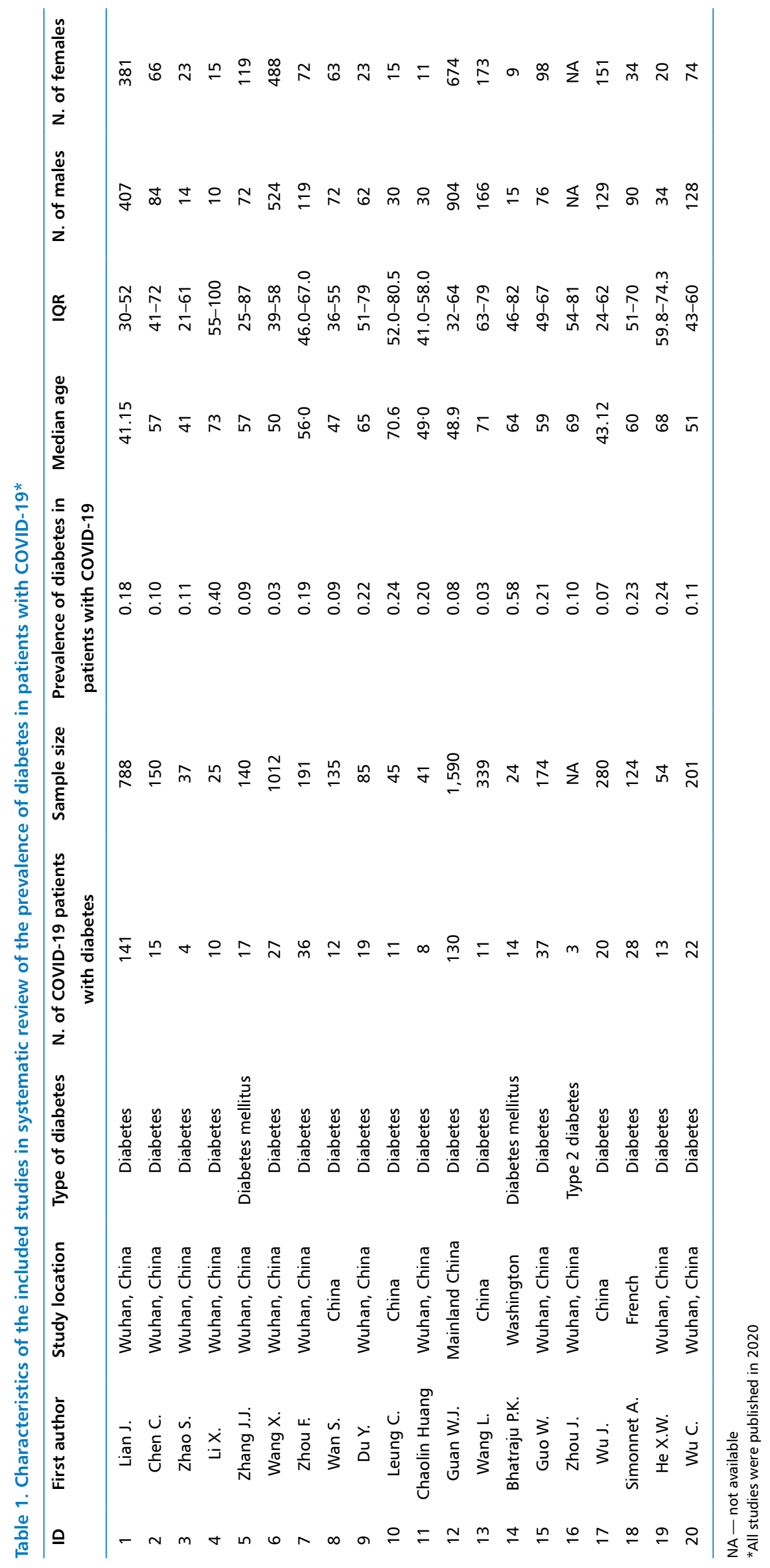


Table 2. Subgroup analysis for prevalence of diabetes in patients with COVID-19*

\begin{tabular}{|c|c|c|c|c|}
\hline Variable & Prevalence & $95 \% \mathrm{Cl}$ & $I^{2}(\%)$ & P value* \\
\hline \multicolumn{5}{|l|}{ Geographic area (Figure 3) } \\
\hline Wuhan, China & 0.15 & $0.10-0.20$ & 91.8 & $<0.001$ \\
\hline Other places in China & 0.10 & $0.06-0.15$ & 94.0 & $<0.001$ \\
\hline Other countries (France and the United States) & 0.39 & $0.04-0.74$ & 91.0 & $<0.001$ \\
\hline \multicolumn{5}{|l|}{ Gender (Figure 4) } \\
\hline Male $<50 \%$ & 0.12 & $0.06-0.17$ & 89.5 & $<0.001$ \\
\hline Male $\geq 50 \%$ & 0.16 & $0.12-0.20$ & 94.9 & $<0.001$ \\
\hline \multicolumn{5}{|l|}{ Age (Figure 5) } \\
\hline Median age $<65$ & 0.13 & $0.1-0.17$ & 94.4 & $<0.001$ \\
\hline Median age $\geq 65$ & 0.19 & $0.08-0.31$ & 90.3 & $<0.001$ \\
\hline
\end{tabular}

*P value for heterogeneity test

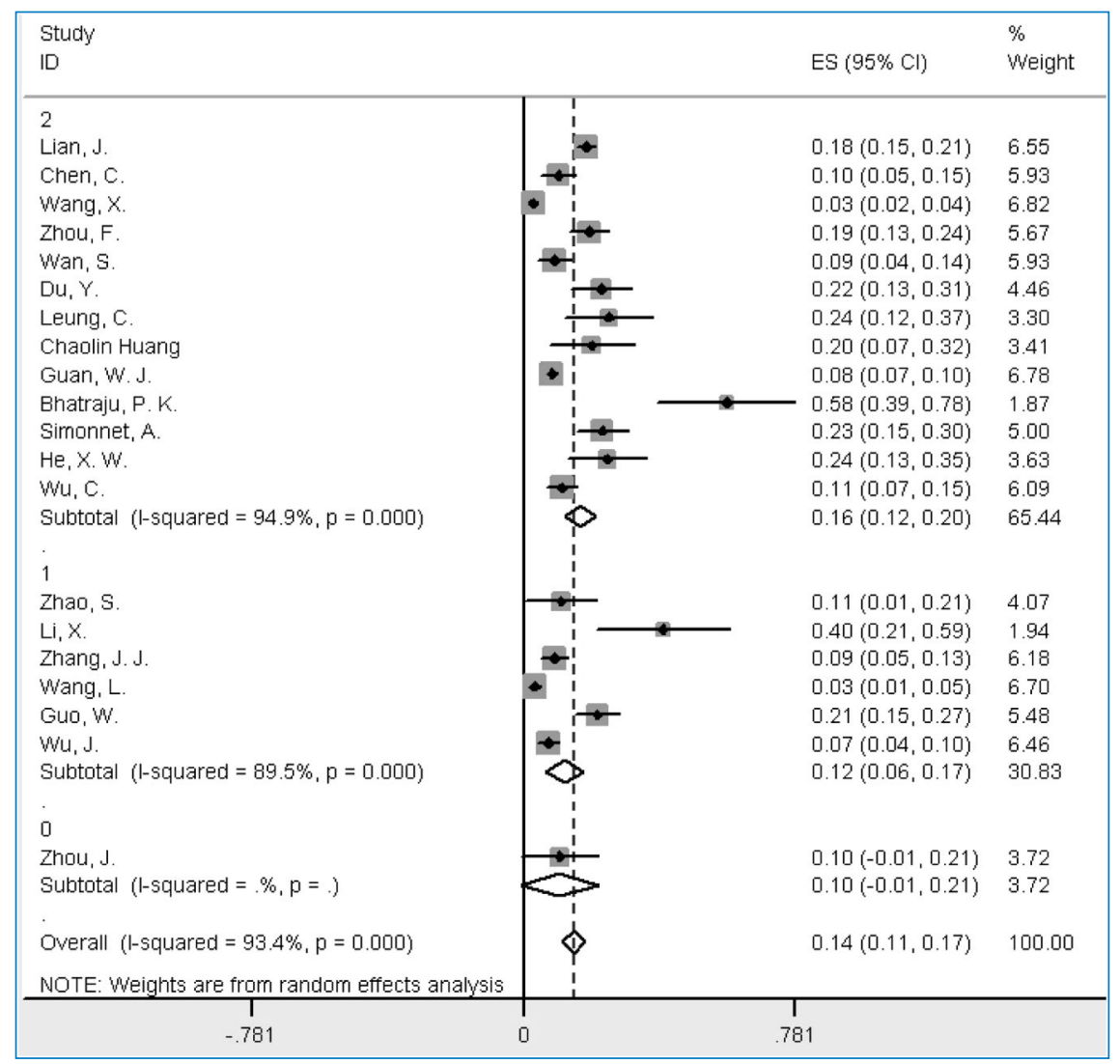

Figure 4. The results of meta-analysis of the prevalence of diabetes in patients with COVID-19 according to gender. $1-$ male $<50 \% ; 2-$ male $\geq 50 \% ; 0$ - ${ }^{* *}$ NA (not available)

included evidence (most of the studies were retrospective) and it may not represent the general population. The sample size was also small in some instances, which may affect the results. The next point was that the different examinations and grades were not uniform for the severe and non-severe patients in the included studies. Also, some studies included patients with more than one common disease. The quality of the studies was not similar, which may affect the results. In addition, most of the studies were conducted in China, and we studied only two countries except China. One of the strengths of the study is that so far, no comprehensive study has been conducted to summarize the prevalence of diabetes in people with COVID-19. 


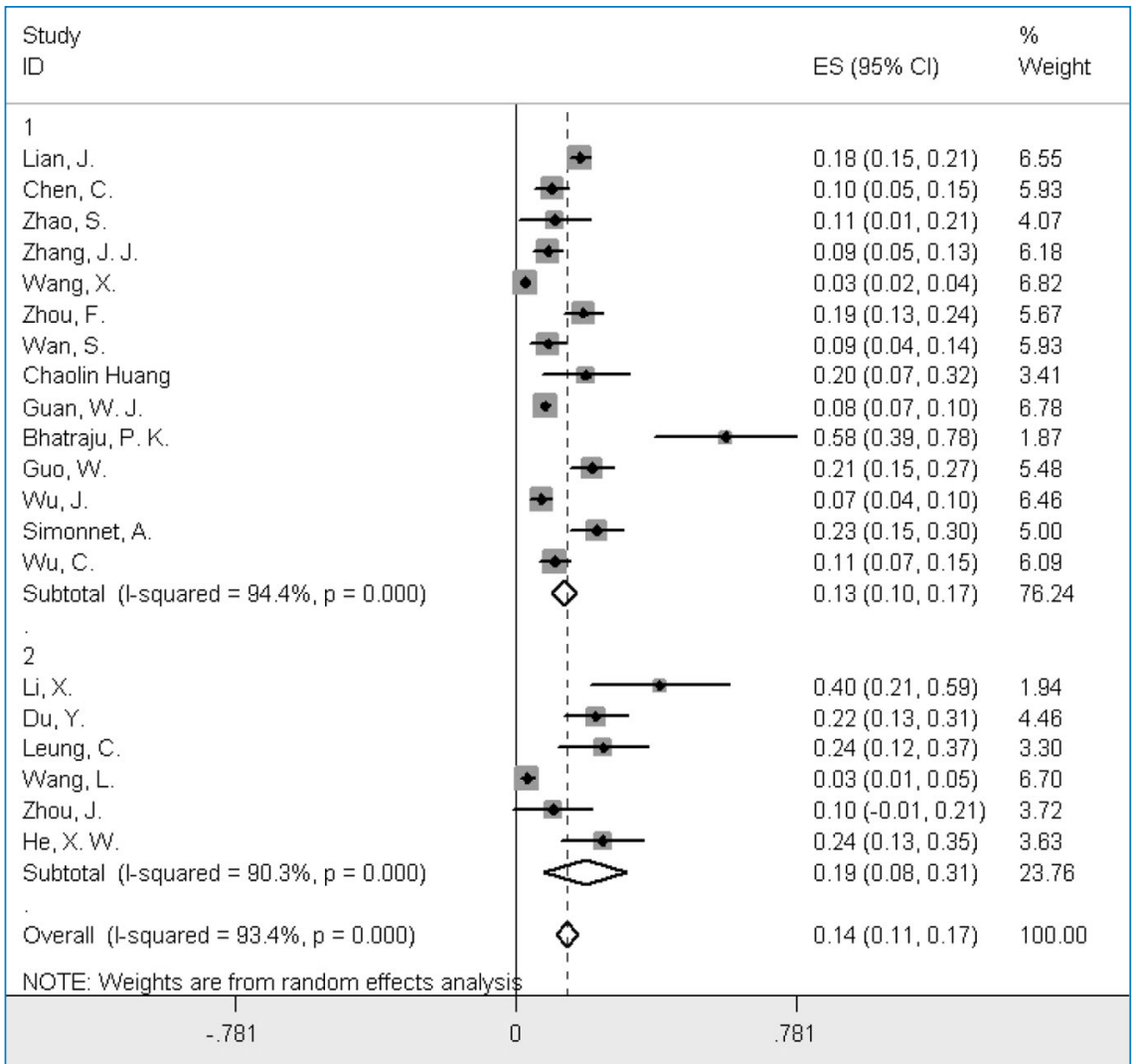

Figure 5. The results of meta-analysis of the prevalence of diabetes in patients with COVID-19 according to age. $1-$ median age $<65 ; 2-$ median age $\geq 65$

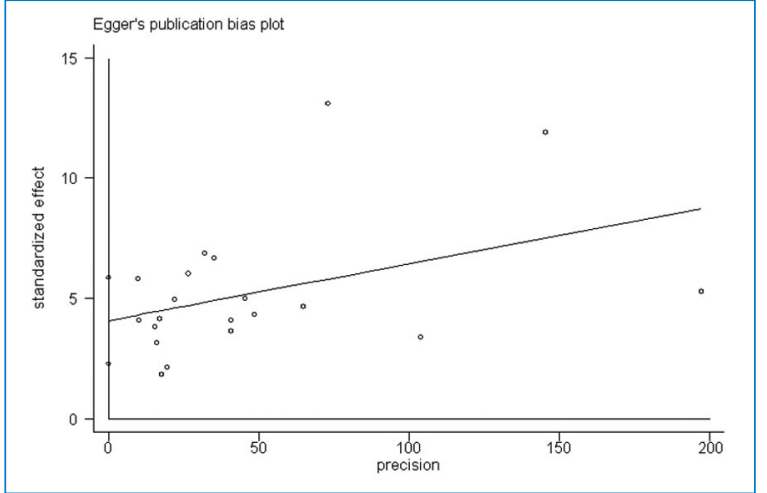

Figure 6. The Egger test for diagnosing publication bias for prevalence of diabetes in patients with COVID-19

\section{Conclusion}

The results of this systematic review showed that diabetes in patients with COVID-19 is not negligible. The prevalence of this disease in different areas can vary depending on lifestyle. According to the results of this systematic review, the prevalence of diabetes in patients with COVID-19 is higher in other countries compared to China. The prevalence of diabetes among

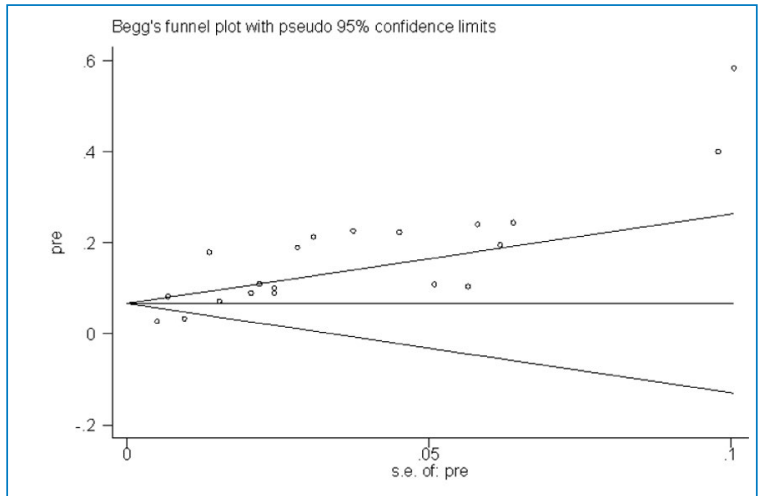

Figure 7. The Begg test for diagnosing publication bias for prevalence of diabetes in patients with COVID-19

COVID-19 patients was also significantly higher in men and elderlies. This evidence may be useful for health policymakers to design suitable preventive and therapeutic interventions in cases with comorbidity of diabetes and COVID-19. It seems that diabetes is an important underlying condition that should be taken into account when developing and implementing interventions to reduce the burden of COVID-19. 


\section{Funding}

This project is funded by the Student's scientific Research Center of the Tehran University of Medical Sciences.

\section{Acknowledgements}

This research was supported by Students' Scientific Research Center, Tehran University of Medical Sciences, Grant (Project Number IR.TUMS.MEDICINE. REC.1399.156).

\section{Conflict of interest}

The authors declare no competing interests.

\section{REFERENCES}

1. Kaiser UB, Mirmira RG, Stewart PM. Our Response to COVID-19 as Endocrinologists and Diabetologists. J Clin Endocrinol Metab. 2020; 105(5), doi: 10.1210/clinem/dgaa148, indexed in Pubmed: 32232480.

2. World Health Organization. Coronavirus disease 2019 (COVID-19) Situation Report -72:Data as reported by national authorities by 10:00CET1 April2020. https://www.who.int/docs/default-source/ coronaviruse/situation-reports/20200401-sitrep-72-covid-19. pdf?sfvrsn=3dd8971b_2 (2.03.2020).

3. Guan WJ, Ni ZY, Hu Yu, et al. China Medical Treatment Expert Group for Covid-19. Clinical Characteristics of Coronavirus Disease 2019 in China. N Engl J Med. 2020; 382(18): 1708-1720, doi: 10.1056/NEJMoa2002032, indexed in Pubmed: 32109013.

4. Fang L, Karakiulakis G, Roth M. Are patients with hypertension and diabetes mellitus at increased risk for COVID-19 infection? Lancet Respir Med. 2020; 8(4): e21, doi: 10.1016/S2213-2600(20)30116-8, indexed in Pubmed: 32171062.

5. Hu Y, Sun J, Dai Z, et al. Prevalence and severity of corona virus disease 2019 (COVID-19): A systematic review and meta-analysis. J Clin Virol. 2020; 127: 104371, doi: 10.1016/j.jcv.2020.104371, indexed in Pubmed: 32315817.

6. Yang J, Zheng Y, Gou X, et al. Prevalence of comorbidities in the novel Wuhan coronavirus (COVID-19) infection: a systematic review and meta-analysis. Int J Infect Dis. 2020.

7. Li Bo, Yang J, Zhao F, et al. Prevalence and impact of cardiovascular metabolic diseases on COVID-19 in China. Clin Res Cardiol. 2020; 109(5): 531-538, doi: 10.1007/s00392-020-01626-9, indexed in Pubmed: 32161990.

8. Wu J, Li W, Shi X, et al. Early antiviral treatment contributes to alleviate the severity and improve the prognosis of patients with novel coronavirus disease (COVID-19). J Intern Med. 2020; 288(1): 128-138, doi: 10.1111/joim.13063, indexed in Pubmed: 32220033.

9. Wang B, Li R, Lu Z, et al. Does comorbidity increase the risk of patients with COVID-19: evidence from meta-analysis.
Aging (Albany NY). 2020; 12(7): 6049-6057, doi: 10.18632/aging.103000, indexed in Pubmed: 32267833.

10. Villabona CV. Commentary: COVID-19 and diabetes. Diabetes Res Clin Pract. 2020; 162: 108138, doi: 10.1016/j.diabres.2020.108138, indexed in Pubmed: 32272191.

11. Leung $C$. Clinical features of deaths in the novel coronavirus epidemic in China. Rev Med Virol. 2020; 30(3): e2103, doi: 10.1002/ rmv.2103, indexed in Pubmed: 32175637.

12. Stang A. Critical evaluation of the Newcastle-Ottawa scale for the assessment of the quality of nonrandomized studies in metaanalyses. Eur J Epidemiol. 2010; 25(9): 603-605, doi: 10.1007/ s10654-010-9491-z, indexed in Pubmed: 20652370.

13. Higgins JPT, Thompson SG, Deeks JJ, et al. Measuring inconsistency in meta-analyses. BMJ. 2003; 327(7414): 557-560, doi: 10.1136/bmj.327.7414.557, indexed in Pubmed: 12958120.

14. Higgins J, Altman D, Sterne J. Assessing risk of bias in included studies. In: Higgins JPT, Green S, eds. Cochrane Handbook for Systematic Reviews of Interventions Version 5.1. 0 (updated March 2011). The Cochrane Collaboration; 2011. The Cochrane Collaboration www handbook cochrane org (accessed 17 May 2018). 2011.

15. Wang X, Fang J, Zhu Y, et al. Clinical characteristics of noncritically ill patients with novel coronavirus infection (COVID-19) in a Fangcang Hospital. Clin Microbiol Infect. 2020; 26(8): 1063-1068, doi: 10.1016/j.cmi.2020.03.032, indexed in Pubmed: 32251842.

16. Bhatraju PK, Ghassemieh BJ, Nichols M, et al. Covid-19 in Critically III Patients in the Seattle Region - Case Series. N Engl J Med. 2020; 382(21): 2012-2022, doi: 10.1056/NEJMoa2004500, indexed in Pubmed: 32227758.

17. Stoian AP, Banerjee $Y$, Rizvi AA, et al. Diabetes and the COVID-19 pandemic: how insights from recent experience might guide future management. Metab Syndr Relat Disord. 2020; 18(4): 173-175, doi: 10.1089/met.2020.0037, indexed in Pubmed: 32271125.

18. Huang $X$, Wei $F, H u L$, et al. Epidemiology and clinical characteristics of COVID-19. Arch Iran Med. 2020; 23(4): 268-271, doi: 10.34172/aim.2020.09, indexed in Pubmed: 32271601.

19. Stein RA. COVID-19: Risk groups, mechanistic insights and challenges. Int J Clin Pract. 2020 [Epub ahead of print]: e13512, doi: 10.1111/ijcp.13512, indexed in Pubmed: 32266754.

20. Lovato A, de Filippis C. Clinical Presentation of COVID-19: A Systematic Review Focusing on Upper Airway Symptoms. Ear Nose Throat J. 2020 [Epub ahead of print]: 145561320920762, doi: 10.1177/0145561320920762, indexed in Pubmed: 32283980 .

21. Wu C, Chen X, Cai Y, et al. Risk Factors Associated With Acute Respiratory Distress Syndrome and Death in Patients With Coronavirus Disease 2019 Pneumonia in Wuhan, China. JAMA Intern Med. 2020; 180(7): 934-943, doi: 10.1001/jamainternmed.2020.0994, indexed in Pubmed: 32167524.

22. Yang $Y$, Liu $X$, Liu $Y$, et al. The effect of diabetes on mortality of COVID-19: A protocol for systematic review and meta-analysis. Medicine (Baltimore). 2020; 99(27): e20913, doi: 10.1097/ MD.0000000000020913, indexed in Pubmed: 32629686. 